PRINT ISSN 1119-8362

Electronic ISSN 1119-8362
Full-text Available Online at

https://www.ajol.info/index.php/jasem

http://ww.bioline.org.br/ja

\title{
Systematic Review on Adverse Effect of Pesticide on Top Ten Importers of African Countries
}

\author{
SINA TEMESGEN TOLERA \\ Toxicology and Environmental Health, Haramaya University of College of Health and Medical Sciences; P.O.BOX, P.O.BOX. 235, Harar, \\ Ethiopia.Institutional Email: Sina.temesgen@haramaya.edu.et; PrimaryEmail: sinatem3@gmail.com; Tel: +251913023634
}

\begin{abstract}
As agricultural production in African countries intensifies; pesticide utilization becomes more widespread and the users are extremely exposed to these pesticides due to lack of pesticide registration scheme; importing highly toxic pesticides; no national plan for pesticide residue; involvement of children and women. The purpose of this systematic review was to review adverse effect of pesticide among top ten imported African countries. In this review, top ten importers African countries were selected based of imported amount for ten years were considered from imported period of 2002 to 2017. The articles were searched from PUBMED, GOOGLE SCHOLAR, and MEDLINE and EMBASE engines. The first leading three continents for pesticides exported were European (48.2\%), Asian (33.7\%) and North America (12.7\%), while the countries were China (14.3\%), Germany (11.8\%) and United States (11.5\%) at the end of 2017. The first three leading importer of African countries were South Africa shared (25.7\%), Nigeria (15.8\%) and Ghana (14.5\%). The three major imported pesticides were Fungicides, herbicides and insecticides. In this review, Ethiopia (827), Kenya (801), and Morocco (542) are the main importers of pesticides until end of 2017. The review also found that farmers were faced with endocrine disruption, carcinogenicity, mutagenicity, teratogenicity, cardiovascular, dermatitis and birth defects. The main associated factor for these problems were low awareness, improper handling of pesticide, and lack of training, and careless disposal of empty pesticides containers. The study concluded that more than one billion US\$ of pesticides sales was carried out into ten African countries. The farmers within these country were faced different health problems due to different determinant factors. Proper training and education should be advised for farmers.
\end{abstract}

\section{DOI: https://dx.doi.org/10.4314/jasem.v24i9.19}

Copyright: Copyright (C) 2020 Sina. This is an open access article distributed under the Creative Commons Attribution License (CCL), which permits unrestricted use, distribution, and reproduction in any medium, provided the original work is properly cited.

Dates: Received: 10 August 2020; Revised: 16 September 2020; Accepted: 22 September 2020

Keywords: Adverse effect, African countries, Import, Pesticide

Over the past era there has been an increase in the development of pesticides to target a broad spectrum of pests, which is a major challenge to the targeted pests causing them to either disperse to new environment and/or adapt to the novel conditions (Quinn et al., 2011).In fact, pesticides assist farmers to minimize potential crop yield loss due to pests, but they may also pose potential hazards to them (Ochieng et al., 2013). Various studies revealed that effects of pesticides on farmers and users is common in developing, which have been documented in Asia (Mancini et al., 2005); in Africa(Ngowi et al., 2007; Oluwole and Cheke , 2009) and Latin America (Hruska and Corriols, 2002). The other study also revealed that African countries are known to consume less than $20 \%$ of the world production of agrochemicals, which are responsible for as much as 1.1 million $(70 \%)$ of the total cases of acute poisoning in farm(Yáñez et al.,2002). As literature indicated only less than $1 \%$ of the total amount of pesticides applied for weed and pest control reach the target pests. A large quantity of pesticides is lost via spray drift to farmer if they do not wear personnel protective equipment/PPE/, the other will be off-target deposition and run-off (Kim et al., 2017). Another relevant factor is that low concentrations of many chemicals may not elicit acute detectable effects in organisms, but they may induce other damage, like genetic disorders and physiological alterations, which reduce life span in the long run (Furio et al.,2015). As study reported, only one third of applicators read the instructions for pesticide use marked on the containers; even fewer (2.5\%) take steps to follow those instructions and almost two third of them didn't read the instructions labeled on pesticide. These are due lack of education, lack of training and inadequate PPE (Tsimbiri et $a l ., 2015)$. Now a day developing countries use only $20 \%$ of the world's agrochemicals, yet they suffer $99 \%$ of deaths from pesticide poisoning. Exposure to pesticides can be may occur through harvesting tasks that may require direct contact with such agents; while, non-occupational pathways may manifest due to direct environmental exposures from heavily contaminated air, water, and soil; or through dietary pathways(Bhardwaj, 2013). The WHO estimates that at the global level, 3 million severe pesticide poisoning episodes occur annually, and of these, a minimum of 300,000 people die, with $99 \%$ of cases being from 
low- and middle-income countries. The study revealed that pesticides are often poorly controlled and widely available, particularly in countries of low and middle income (Abdou et al., 2018). Based on these evidences, the implication of pesticide use and spraying practices on users' health is particularly important in agriculture production systems (Hossain et al., 2004). Moreover, majority of pesticide sprayers mixing of pesticides may alter chemical properties, result in potentiation, and thereby increase detrimental effects (Barchańska and Baranowska, 2009). One of the efforts to improve farmers' pesticide handling practices and reduce potential hazards of the chemicals is to fix safety labels on pesticide containers to alert users of potential risks (Oluyede and Festus, 2007). Farmers are also occupationally exposed to several potentially harmful environmental agents other than pesticides] (Okonya and Kroschel, 2015). As various studies indicated countless pesticides chemicals are environmentally stable, prone to bioaccumulation, and toxic to human and other living organisms and environmental contamination to pesticides residues, including physical and biological degradation products(Clarke et al., 2005) . Some Pesticides, example, insecticides combat insect growth or survival, herbicides act against plants, weeds, and grasses, rodenticides tight against rats and other rodents, avicides act against bird populations, fungicides attack fungi, and nematicides combat nematodes (Nicolopoulou, 2016). The global pesticide market divided according to the type of pesticide is as follows: $42.48 \%$ herbicides, $25.57 \%$ insecticides, $24.19 \%$ fungicides, and $7.76 \%$ other types of pesticides (WHO-FAO, 2018). Pesticides grouping can also rely on their chemical structure and they are belonging to different chemical classes (Andert et al., 2016). Pest management of fruits and vegetables by small farmers in Africa have developed anarchically in a fuzzy regulation framework (Jepson et al., 2014). In Africa, surveys indicate that a small number of farmers consistently use appropriate PPE due to cost and hot humid climate that make wearing such PPE uncomfortable; as well, accidental ingestion of contaminated crops is a major source of accidental poisoning as reported many African countries (Negatu et al., 2016) . In addition, different risk factors have been declared that increase toxicity of pesticides especially in developing countries including: lack of pesticide registration scheme; importing highly toxic pesticides; no national plan for pesticide residue; lack of safeguards; and improper handling of pesticides; ignoring of re-entry and pre harvest intervals; involvement of children and women in farm work; illiteracy regarding the basis of good agriculture practice (Zineb et al., 2014). These risk factors could either increase the like hood of higher exposure to pesticides, or increases the toxic effects on human body [Kim et al., 2017; Mulu et al., 2018). Thus, the reviews found that there were health problems within African countries due different associated factors. Therefore, the objective of review is to pursue the adverse effect of pesticide on top ten imported African countries farmers.

\section{MATERIAL AND METHODS}

Selection Criterial of Sites: Top ten importers of African Countries were selected based on Food and Agriculture Organization Statistical database (FOA, 2014). By default five sub regions of African were included: from North African countries: Egypt and Morocco; from Western Africa: Ghana and Nigeria; from East African countries: Ethiopia and Kenya; from Southern Africa countries: South Africa; and from Central Africa countries Cameroon was selected review.

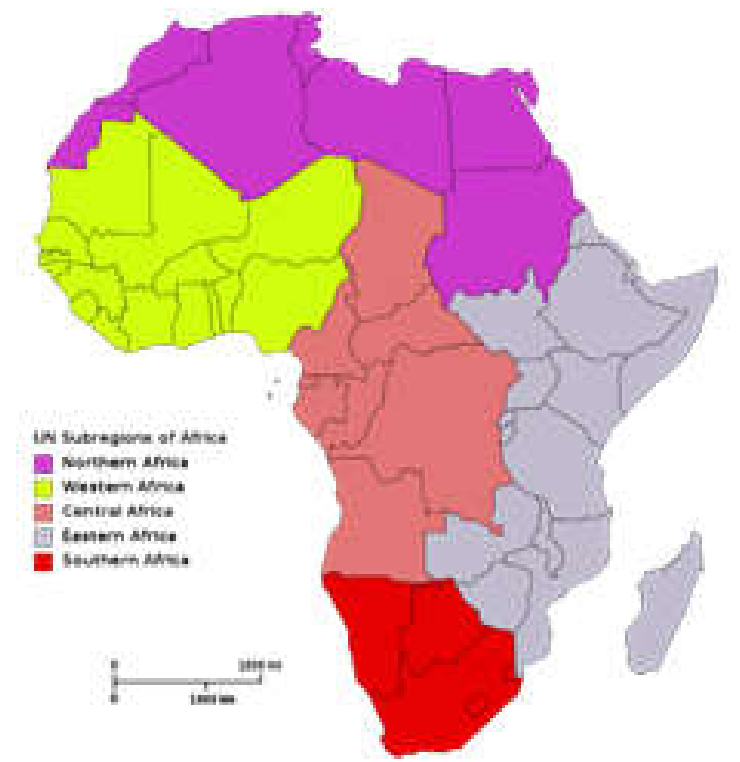

Fig 1 Article Review were Retrieved from selected Sub Region of Africa adopted from UN

Article Searched: Reviewers were selected all relevant studies with language restriction that is by English. Information reviewed and the bibliographies of articles were identified further eligible criterial in each countries using Google scholar, PubMed, Scopus, and Science Direct, Index Medicus/WHO/EMdR, Elsevier, Cochrane Library from 2003 to 2019.

Article Screened Process: Figure shows that a total of 210 articles and texts were collected based on the following key words: adverse, effect, pesticide, farmers and included African countries, and finally 43 articles and texts published between 2002 and 2019 were reviewed. 


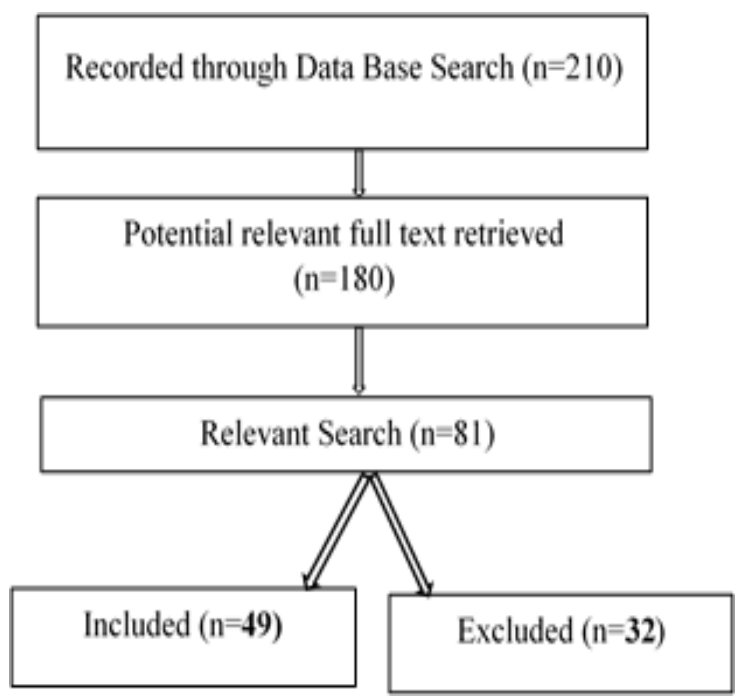

Fig 2 Searching process of Systematic Review of Pesticide effect on farmers of African countries

Validity Assessment: From each country the report on compliance with supplementation as described. Thus, reviewers included only information available from publications. Thus, the data bases and the extracted documents were evaluated and checked to make the study more valid and reliable.

Data Extraction and Synthesis: The data were extracted from each eligible study using datacollection form resolved discrepancies by consensus.

Methodological Quality: The reviewers independently assessed the methodological quality of the studies using a predefined check-list, as suggested specially for the Cochrane Database of Systematic Reviews. The original data were not modified.

Data Procedure and Ethics: We checked all cross sectional studies were approved at each study settings; while, all procedures involving on sampling of blood subjected according human ethics. Different Kits were used for detection pesticide in blood, crops and food were used.

\section{RESULT AND DISCUSSION}

Rank of Continents for Pesticide Exporters: Based on the Food and Agriculture Organization Corporate Statistical Database website disseminates statistical data collected and maintained by the Food and Agriculture Organization /FOASTAT/, European countries, Asian, North America, Latin America, Africa and Oceania were $48.2 \%, 33.7 \%, 12.7 \%, 3.8 \%$, $1 \%$ and $0.6 \%$ exported pesticides, respectively to other countries during 2018 (Figure 3). As showed above figure shows, worldwide sales of pesticides exports by country totaled US $\$ 36.5$ billion at the end of 2017.

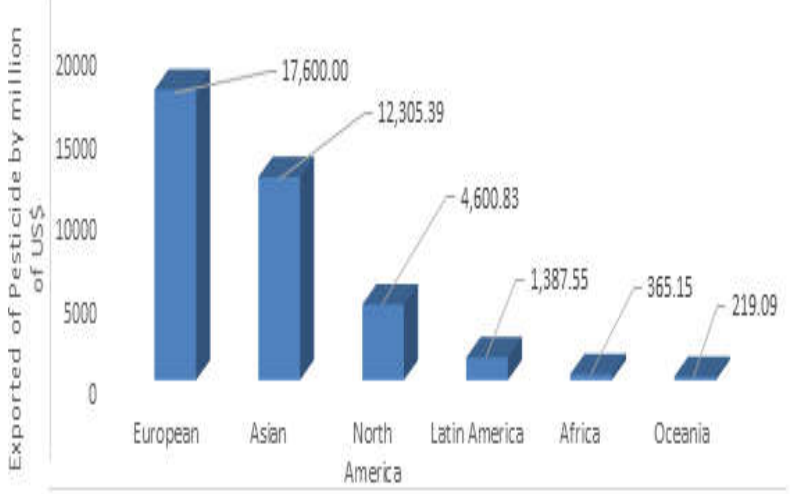

Fig 3 Rank of Continents for Pesticide Exporters during, 2018

European countries generated the highest international sales from exported pesticides during 2018 (at the end of 2017$)$ valued at $\$ 17.6$ billion or almost half $(48.2 \%)$ of the global total. In second place were Asian exporters at $33.7 \%$ while $12.6 \%$ of worldwide pesticides shipments originated from North America. Smaller percentages came from Latin America (3.8\%) excluding Mexico but including the Caribbean, Africa $(1 \%)$ and Oceania $(0.6 \%)$ mostly Australia and New Zealand (Scott DeCarlo, 2013).

Top Ten Pesticide Exporters of World Countries: When we compare all worlds countries those exported pesticide, the first ten top countries are China, Germany, United States, France, India, Belgium, United Kingdom, Spain, Israel and Italy (Figure 4).

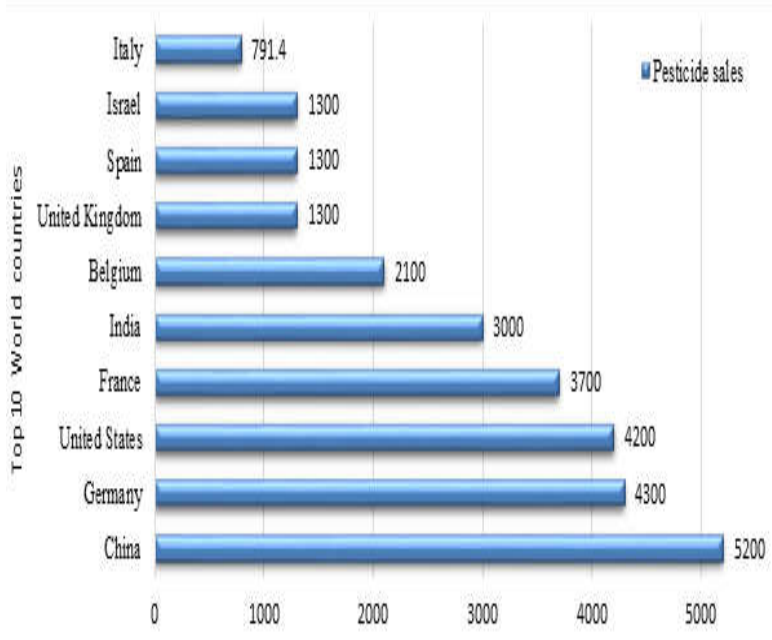

Fig 4 Top Ten Exporters of Pesticide to African Courtiers by Million Dollar during 2017

The Food and Agriculture Organization statistics revealed that China: US\$5.2 billion (14.3\% of total exported pesticides); Germany: $\$ 4.3$ billion (11.8\%); USA: $\$ 4.2$ billion (11.5\%); France: $\$ 3.7$ billion 
(10.1\%); India: \$3 billion (8.1\%); Belgium: $\$ 2.1$ billion (5.7\%); United Kingdom: \$1.3 billion (3.7\%); Spain: $\$ 1.3$ billion (3.6\%); Israel: $\$ 1.3$ billion (3.5\%); Italy: $\$ 791.4$ million $(2.2 \%)$ were the 10 countries, which were the highest dollar value worth of pesticides exported at the end of 2017 (FOA, 2018)

Top Ten Importers of African countries and Health problem of Pesticide: All importers of African countries were compared using data from FAOSTAT data a time series from 2008 to 2017 . The first ten leading importer of African countries(Total $=1,305,968,305 \$$ ), about South Africa [3.356 million $\$(25.7 \%)$ ], Nigeria [2.060 million $\$(15.8 \%)$ ], Ghana [1.896 million \$(14.5\%)], Morocco [1.496 million $\$(11.5 \%)]$, Egypt [1.239 million $\$(9.6 \%)]$, Algeria [0.861 million $\$(6.6 \%)]$, Cameroon [ 0.58 million $\$(4.5 \%)$ ], Ethiopia [0.563 million $\$(4.3)$, Tanzania [0.504 million $\$(3.9 \%)]$ and Kenya [0.501 million $\$(3.8 \%)]$ of pesticides were imported from 2008 to 2017(Figure 3).

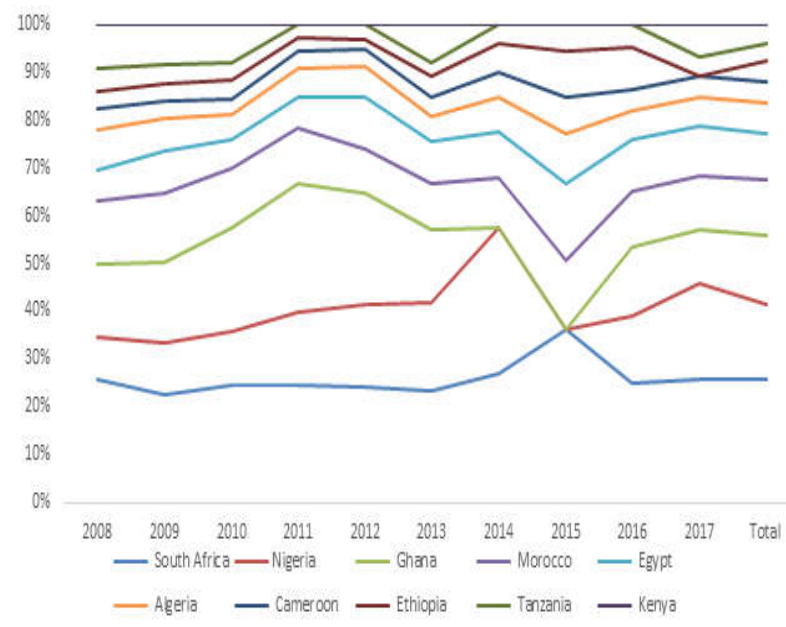

Fig 5 Top Ten Importer of Pesticide among African countries during 2008 to 2017

Regarding to health problems, among all African countries, the first top ten were considered to evaluate the health effect of pesticide among sprayers, users and farmers. Accordingly, the review shows that about 3796 of sprayers, farmers and pesticide users were involved. Of these, South Africa (269), Nigeria (200), Ghana (354), Morocco (542), Egypt (102), Cameroon (241), Ethiopia (827), Tanzania (360) and Kenya (801) users. In the overall assessment review of health problems, malaise, headache, nervous system anxiety, depression, cardiovascular, swelling, respiratory cough, sneezing, dyspnea and wheezing, and water brush gastrointestinal pain, vomiting, diarrhea, bloody, itchy ear, nose and throat, skin rash, eyes itchy painful symptoms were identified among users, famrers and sprayers. These workers faced with endocrine disruption, carcinogenicity, mutagenicity, teratogenicity diseases due to exposure of pesticide.

The associated factors were low awareness, low attitude and poor practice of pesticide for pest management. Majority of the farmers' perception was less than half percent (50\%) and lack of training, lack of information were observed. In addition to these factors, height and weight are the other associated factors. Majority of them used fungicides, herbicides and insecticides for protection of pest from their crops and residual of pesticides were found in crops and aquatic. Food and Agriculture Organization statistics/FOASTAT/ reported that African countries did USD 548 billion import business and USD 476 billion export business at the end of 2017. According to the export statistics from China Customs, export volume of pesticides during January to November in 2015, African markets represented $13.9 \%$ of the total export of pesticides from China and concerned 44 countries. The amount of export value for African countries constitutes $85.9 \%$ of the total export value to Africa from China (Mulu et al., 2018). Majority of importers from are African countries (FOA, 2018). The first ten top African countries were- South Africa, Nigeria, Ghana, Morocco, Egypt, Algeria, Cameroon, Ethiopia, Tanzania and Kenya, which were valued 3.356 million $\$(25.7 \%), 2.060$ million $\$(15.8 \%)$, 1.896 million $\$(15.5 \%), 1.496$ million $\$(11.5 \%)$, 1.239 million $\$(9.5 \%), 0.861$ million $\$(6.6 \%), 0.58$ million $\$(4.5 \%), 0.563$ million $\$(4.3 \%), 0.504$ million $\$(3.9 \%)$ and 0.501 million $\$(3.8 \%)$, respectively. According to this review, South Africa is the largest importer of pesticides from African countries. In this country, pesticides are used in almost every facet of our everyday lives; ensuring the quantity and quality of food we eat to managing the number of rodents and insects in our homes (Jean et al., 2018). Literature shows that it is evident that there is a vast amount of pesticides present in the South African environment, there is very limited data on the production of pesticides. In the year of 2002, about 2800 -tonnes of insecticides were produced (SSA, 2003). Of total use of pesticide, $50 \%, 41 \%$ and 85 were accounted by herbicides, fungicides and insecticides, respectively. The residual of these pesticides was analyzed on different crops: maize [0.29], potatoes [0.23], citrus [0.11], grapes [0.06], and sugarcane [0.06], which are more than allowable than maximum recommendation for residual of the pesticides. Even if, the usefulness of pesticides cannot be denied, the negative environmental and human health effects cannot be ignored in South Africa (Quinn et al., 2011). The Survey study was conducted on $269(\mathrm{n}=269)$ who used pesticides in South Africa. As study reported farmers were exposed to different health problems. To study 
these problems, the proximity of farm was considered to determine effect of pesticide. Accordingly, the individual who were resided in closer proximity to agricultural pesticide spraying faced to asthma, birth defect, mutagenicity, teratogenicity and neurotoxicity than far from farm sites (Ochieng et al., 2013). This suggests that 'farm residence' are located closer to the farmer (usual farmers) are exposed to higher intensities of, spraying than far from farm sites. High height and weight of workers were highly exposed as compared to short farmers, which was other associated factors for pesticide exposure. Thus, the study concluded that lack of training, low awareness, proximity of the farm, poor utilization of pesticide and anthropometric of the farmers were associated factors for exposure of pesticide among farmers (Ochieng et al., 2013).

Nigeria is the second importer from all African countries and the first importer of pesticides among West Africa countries. The other study also reported from the same place states the majority of farmers (74\%) used inorganic fertilizers and 26\% used organic fertilizers (compost manure) (Chikamso, 2018). To determine the effect on human being, food test carried out on 217 different food items such as e were observed in vegetable, tuber, cereals, cow, pig and goat were detected. Thus, the study reported that the residual of pesticides like DDT, Aldrin and Dieldrin were above maximum allowable concentration level which ranged from 1.2-2160 $\mu \mathrm{g} \mathrm{kg}-1$ (Erhunmwunse $e t$ al., 2014). In case of survey, 300 farmers $(n=300)$, majority of them exposed to health problems such as dermatitis, allergy sensitization reaction, birth defects, morbidity, impaired immune function, causes of cancer, cardiovascular disease, and neurobehavioral disorder. This is why? Most of the farmers (65\%) reported that they could not read agrochemical application instructions, $92 \%$ of farmers were exposed to agrochemicals during application, and most farmers (73\%) reported falling sick after exposure to agrochemicals. In addition, farmers lacked the information and poor legislation (Chikamso, 2018).

Ghana is the third from all African and the second highest importer of pesticides Western African countries. Insecticide, herbicide and fungicides are the major pesticides. To determine the effect of these pesticides an active ingredients of stored cocoa pesticides was detected from $5 \mathrm{~m}$ and $10 \mathrm{~m}$ away from storage structures where the various treatment regimen was imposed. Accordingly, Allethrin (0.083), Deltamethrin (0.277), Cypermethrin (0.167) and Cyhalothrin (0.011) were Identified pesticide from wall paint $10 \mathrm{~m}$, which are maximum recommended levels of Cacao, they have potential to cause health effect on human and other organisms(Azalekor et al., 2019) . Regarding to farmers $(n=254)$ who used pesticides were reviewed. Among these, the highest exposed to bad odor was the commonest complaint (38\%) followed by sneezing $(28 \%)$ and headache (16\%) (Azalekor et al., 2019). Similar study conducted in this country also shows that health problem symptom such as headache $(37 \%)$, sneezing (34\%), sweating (13\%), and numbness in the fingers $(11 \%)$, tiredness $(3 \%)$ and runny nose $(3 \%)$, were observed among farmers of Ghanaians. The study revealed that educational level, occupation of the participants, frequency of pesticide application, use of protective clothing, knowledge and adherence to basic rules on pesticide application, and effectiveness of pesticide use as pest control strategy had attributed to exposure to pesticides (Azalekor et al., 2019). Literature review shows that $35.6 \%$ the respondents had low awareness. Also the socioeconomic variables are labor, age, marital status, household size, and years of education, extension contacts, farm size, and quantity of pesticides were significantly influencing agrochemical use that is pesticides within their farms (Mabe et al., 2017).

Moreover, Morocco, is the fourth and first highest importer of pesticide from Northern Africa countries. The major pesticides were insecticides $(19 \%)$, fungicides $(31 \%)$, herbicides $(35 \%)$ insecticidesacaricide (4\%) and nematicide insecticide and (1\%). Some of these substances are classified as to its carcinogenicity risk in group 1, 2A and 2B according to International Center for Research on Cancer. Thus, the farmers use carcinogens products: $47.3 \%$ are already exposed and very few of these producers are confronted with the health rules for the phytosanitary treatment. For the sake of residual analysis potato vine crops and orchards, were performed for the most record and the important use of pesticides and the residual was maximum allowable permits, which is risk on human health (Imane et al., 2016). Regarding to farmer perceptions, 542 farmers $(\mathrm{n}=542)$, who used pesticides were considered in this review. From 140 farmers, more than $2 / 3$ do not use effective/any measure of security, and $50 \%$ not respect the dose prescript when they spread the phytosanitary product on their crop; only $20 \%$ affirmed they respect both the manufacturer notification of use and the dose (Benaboud et al., 2014). In same place, the study was dealt with 402 farming households (Imane et al., 2016). Most (3.73\%) of them reported that they had skin irritation, headaches, and eleven having respiratory problems after application of pesticides. The consumption of alcohol $(p=0.0057]$ and tobacco $[p=0.052]$ had a strong correlation with the return of these health problems (Imane et al., 2016). 
Furthermore, the study conducted in Egypt, the second importer of pesticides from Northern African countries. The most frequently used pesticides by the subjects were inorganic compound, organophosphates, carbamates and pyrothrids. The major pesticides used insecticide i.e Zinc phosphide $(97.14 \%)$ followed by chlorpyrifos and Malathion (94.3\%). To detect the health problems of pesticides, experimental study conducted near Cairo, Alexandria, Damietta, and Manzala Lake shows that the mean concentrations of pesticides at all sampling locations was higher than national recommendation levels Alachlor $(199.6 \mu \mathrm{g} / \mathrm{L}>0.4 \mu \mathrm{g} / \mathrm{L}) \quad, \quad$ Metolachlor $(10.4 \mu \mathrm{g} / \mathrm{L}>3.2 \mu \mathrm{g} / \mathrm{L}), \quad$ Pendimethalin $\quad(2.2>1.8)$, Atrazine $(4.1 \mu \mathrm{g} / \mathrm{L}>3 \mu \mathrm{g} / \mathrm{L})$ and Malathion $(4.2 \mu \mathrm{g} / \mathrm{L}>3.7 \mu \mathrm{g} / \mathrm{L})$. This finding shows that such amount of concentration has the potential to affect the ecological, environmental and also if anybody consumed through the water or food, they could cause cancer, endocrine disrupting and neurotoxic effect on farmers (El-Wakeil et al, 2013). Also to determine the effect of pesticides among market workers and sprayers the farmers the blood sampling was performed. Accordingly, about 76.7, 92.5 and $100 \%$ of farmers, market workers and spray workers had varied levels of insecticide residues was found in their blood, respectively. This shows that the proximity of pesticide and the occupation among pesticides users are the most associated factors for risk of pesticides. As study indicated spray workers had high amount of residues detected in their blood had chlorpyrifos $(84.0 \%)$, profenofos $(72.0 \%)$, lambda-cyhalothrine $(64.0 \%)$, pirimicarb $(52.0 \%)$, carbofuran $(28.0 \%)$ and triaziphos $(24.0 \%)$ residues above the recommended "Allowable Dietary intake levels because of their extensive and frequently use (El-Wakeil et al, 2013). Concerning perception of farmers, of $170(n=170)$ of farmers, majority of study subjects were not taking the necessary precautions to prevent hazards associated with their use. The results of survey revealed that 60.0, 6.7 and $12.0 \%$ of farmers, market workers and spray workers did not wear protective apparels (such as overall, boots, gloves, etc.). The farmers did not use mask while 26.7 and $24.0 \%$ of market and spray workers used masks. About 20 and $52 \%$ of farmers and spray workers use hats, but pesticides marketing did not use them. Also 83.3 and $86.7 \%$ of farmers and market workers were smoke or drink and eat food during mixing and during applying pesticides, while about $40.0 \%$ of pesticide sprayers practice these habits. About $16.7 \%$ farmers and only $20.0 \%$ pesticide spray workers do have knowledge on re-entry periods. Majority of farmers do not bother to read the pesticide labels and contrarily $80 \%$ pesticide market workers read labels. Interestingly $20.0,13.3$ and $40.0 \%$ of farmers, market workers and spray workers, respectively, reported that they re-used the pesticide containers, while the majority of farmers and spray workers ( 80.0 and $60.0 \%$, respectively) leave it in the field after use (Selim and Popendorf, 2009).

Algeria is the third importer of the Northern Africa. The main pesticides were insecticide, herbicides, fungicides and nematodes. The residual pesticides was performed to determine the concentration of levels in vegetables and crops. The study confirmed that chlorpyrifos-ethyl $(0.028 \pm 0.001 \mathrm{mg} / \mathrm{kg})$, fenitrothion $(0.68 \pm 0.004 \mathrm{mg} / \mathrm{kg})$, metalaxyl $(0.048 \pm 0.015 \mathrm{mg} / \mathrm{kg})$, procymidon $(0.046 \pm 0.02 \mathrm{mg} / \mathrm{kg})$ and triadimenol $(0.035 \pm 0.003 \mathrm{mg} / \mathrm{kg})$, which were higher than maximum permissible limits of pesticides residuals (Saidi et al., 2016). On the other hands, blood analysis was done to determine disrupt reproductive biomarkers. All subjects and blood serum was stored and assayed for luteinizing hormone (LH), follicule stimulating hormone (FSH), testosterone (T), estradiol (E2), free thyroxin (FT4), total triiodothyronine (TT3) and thyrotropin (TSH). The obtained results showed a significant decrease in the LH concentration of the greenhouse workers compared to the control. As study revealed there was also a significant depletion in the FSH and testosterone levels of all workers exposed to pesticides. Serum concentrations of TT3 have not been affected during pesticides' exposure. Thus, the study concluded that exposure to pesticides could disrupt some reproductive biomarkers, particularly in those working in closed area (Soltani, 2014).

Cameroon is one of the highest importer from Central Africa. Insecticides, fungicides and herbicides were the major pesticides used by farmers. The most common of residual of these pesticides was found in tomato, pepper, onion, cabbage, amaranth, okra, nightshade, Eggplant, mallow and hot sweet, and their residuals were more than daily allowable intake (Nkontcheu and Brice, 2017). Concerning farmer and sprayers, about 241 of farmers $(n=241$, from two studies), who used pesticides were considered. Of these, $137 \quad(\mathrm{n}=137)$ the farmers reported nausea $(29.9 \%)$, headache $(12.4 \%)$, fatigue $(12.4 \%)$, eye problem $(16.8 \%)$, dizziness $(8.7 \%)$, catarrh $(1.4 \%)$, itches $(4.4 \%)$, nervousness $(12.4 \%)$, cough $(4.4 \%)$, sweating $(3.6 \%)$, vomiting $(2.9 \%)$, diarrhea(7.3), restlessness $(3.6 \%)$ and anxiety $(2.9 \%)$ of them had health problems (Nkontcheu and Brice, 2017). About $96.4 \%$ of the farmers were mainly used manual with $54 \%$ of users experiencing health problems. Because of the lack of funding and training, 19.7\% sprayed pesticides without protection. For the Restricted Entry Interval (REI), $43.1 \%$ entered the field in less than $12 \mathrm{~h}$ after pesticide application. Some respondents $(54.7 \%)$ said they hadn't received any training on pesticide 
application while $20.4 \%$ of respondents failed to follow recommended doses. About $62.1 \%$ of pesticides users for domestic purposes. Some farmers $(46.7 \%)$ have once heard about pesticide related accident while $14.6 \%$ suffered from pesticide intoxication, the prevalence being significantly higher in males $(p<0.05)$. Therefore, the study concluded that there is a need to reregulate the pesticides sector, assess ecological risk and the bioaccumulation potential of these pesticides (Nkontcheu and Brice, 2017). The other study also indicated that from 104 $(\mathrm{n}=104), 75 \%$ them received, and have never received any training on pesticide use practices and health effects. Based on farmers' health problems: skin irritation, impairment of the central nervous system, visual problems, and respiratory difficulties were common. This is due to absence of farmer training further increases the danger of pesticide misuse (Abang et al., 2006).

Moreover, Ethiopia is the highest importer of pesticide among Eastern African countries. From this study, Insecticide (66\%) and Fungicide (33\%) were mainly used amongst the farmers of Ethiopia (Mengistie et al., 2017). The country is now struggle to eradicate the poverty through agriculture-Industry linkage. However, majority of the farmers in this country are illiterate (Naidoo et al., 2006). A survey was conducted in 827 farmers $(n=827)$, who used pesticides were considered in this review. Of these, 516 farmers $(\mathrm{n}=516)$, who used pesticides had health problems stated as I-VI. (I) such as nervous system, headache, dizziness, excessive sweeting, salivation, confusion, weakness, anxiety and loss of consciousness (79\%); (II) such as cardiovascular and Bradycardia (40\%); (III) such as gastrointestinal, vomiting, diarrhea and abdominal cramp (58\%); (IV) such as respiratory system, Chest tightness, dyspnea, morning cough, day/night time cough, shortness of breath and wheezing (58\%); (V) such as ocular and eye tear (54\%); (VI) such as dermatologic, rash on hand and skin rash (51\%)(Nigatu et al., 2016). On the other hands, from all participants $(\mathrm{n}=516), 26 \%$ was the prevalence of Acute Pesticide Intoxications/API/ in the past year among the residents in the study area, which was higher in the population living close to the flower farm $(42 \%)$ compared to those living far away (11\%), Adjusted odd ratio [AOR $=3.2 ; 95 \% \mathrm{CI}(2.2-$ 4.8)] for age, gender \& education. A group living close to the farm \& working there had significantly more API (56\%) than those living close \& didn't work there (16\%) [AOR: 3.0, $95 \%$ CI (1.8-4.9)]. Flower farm workers reported more API $(56 \%)$ than those not working in the flower farm (13\%), [AOR: 4.0, $95 \%$ CI (2.9-5.6)]. This simply indicated that the proximity of pesticide exposure matter for high severe health effect (Nigatu et al., 2016). Therefore, usually farmers are working with close farm areas could affect by health problems. Moreover, the other study conducted in this country shows that from 311 farmers $(n=311)$, about $(44 \%),(23 \%)$ and $(43 \%)$ of them had the knowledge, attitude and practice of the farmers, respectively, which is less than half percent $(50 \%)$, which need to improve in order to prevent the risk of the pesticide(Mengistie et al., 2017).

Tanzania is the second importer of pesticides next to Ethiopia. The study reported that farmers were used 81 formulation produced with 54 active ingredients, which consists Carbamates and Organophosphorus (29\%), Pyrethroids and pyrethrins (14\%), organochlorines(17\%), and other such as fungicides, fumigants, herbicides and rodenticides $(40 \%)$. Regarding to farmers, 360 of farmers and sprayers $(\mathrm{n}=360)$ who used pesticides were considered in this review. The study conducted by Ngowi et al. (2002) revealed that, of 133 sprayers $(n=133)$, they faced to health problems such as cough $(33.8 \%)$, headache $(30.1 \%)$, feeling weak (22.6), difficult in seeing $(22.6 \%)$, dizziness (15\%), abdominal pain (12.8\%), sweating $(12.8 \%)$, nausea $(11.3 \%)$, excessive salivation $(10.5 \%)$, diarrhea $(8.3 \%)$ and vomiting $(6.8 \%)$ (Ngowi et al., 2002). In other way, from the total of 106 rice farmers $(n=106)$, more than half $(62 \%)$ did not see any risks with pesticide use for human health, and environment. Majority (65\%) did not believe that pesticides could have any negative effects on other organisms than the targeted pests. Of studied, safety instructions were seldom (50\%) included when pesticides were purchased. Written safety instructions were often only in English, which could not be understood by the farmers, who often were illiterate. More than half of the farmers did not use any PPE during mixing or application of pesticides. Most of the, often mixed pesticides and rice husks together with their bare hands, and just half of them specifically mentioned that they washed their hands afterward. Kitchen utensils were often used for preparing the mixtures. Only two respondents mentioned that they had specific for pesticides (Stadlinger et al., 2011). The other study conducted on 121 farmers $(n=121)$ reported that $93 \%$ of farmers was reported past lifetime pesticide poisoning. The agents reported as responsible for poisoning were Organophosphates (42\%) and WHO Class II agents $(77.6 \%)$. Storage of pesticides in the home was reported by $79 \%$ of farmers (Lekei et al., 2014). The study reported that education levels were significantly less likely to store pesticides in their home (PRR $\mathrm{High} / \mathrm{Low}=0.3 ; 95 \% \mathrm{CI}=0.1-0.7)$ and more likely to practice calibration of spray equipment (PRR $\mathrm{High} /$ Low $=1.2 ; 95 \% \mathrm{CI}=1.03-1.4)$. However, 
knowledge of routes of exposure was not associated with safety practices particularly for disposal, equipment wash area, storage and use of PPE. Thus, this study concluded that a high potential for pesticide exposure, which needs comprehensive interventions to reduce both exposure and health risks, including training, improvements in labeling, measures to reduce cost barriers (Lekei et al., 2014).

The last and third importer of pesticides among Eastern African country is Kenya.

The major type of pesticides used by farmers were insecticides $(53 \%)$, fungicides $(28 \%)$, herbicides $(16 \%)$ and others $(3 \%)$.

From these Carcinogens (43\%), bad for health (60\%), and very harm full $(47 \%)$ of the due to pesticides. As this study indicated about $35 \%$ of the volumes belong to the organophosphates, $25 \%$ carbamates, $22 \%$ pyrethroids, $7 \%$ tetranortriterpenoids, and $7 \%$ inorganics. Of the pesticides, $8 \%$ were classified as highly hazardous compounds by WHO, 25\% as carcinogens, while $43 \%$ are said to be possible carcinogens.

Approximately $60 \%$ of the pesticides indicated to be bad actor chemicals, $64 \%$ to be ground water contaminants, and $47 \%$ very harmful to beneficial insects (WHO, 2018). Calculated mean EIQ-values were 22, 6 and 82 for farm workers, consumers and the environment, respectively, with an overall average of 37 (Macharia et al., 2009).

The literature found that symptoms of health problems due to pesticide exposure were showed as I-X, which were observed among farmers of Kenya:

I stands for general malaise, headache (47.4\%);

II: nervous system anxiety, depression and loss of consciousness $(4.9 \%)$;

III: cardiovascular, chest pain and leg swelling $(30.8 \%)$;

IV: respiratory cough, sneezing, dyspnea and wheezing (34.5\%);

$\mathrm{V}$ : gastric heat burn and water brush (24.1\%);

VI: such as gastrointestinal abdominal pain, vomiting, diarrhea, bloody, vomitus or jaundice (29.6.3\%);

VII: nose and throat itchy painful ear, nose and throat $(7.7 \%)$;

VIII: skin, skin rash, itching or other skin conditions $(29.6 \%)$;

IX: such as eyes itchy painful or tearing eyes (22.2\%); $\mathrm{X}$ : such as joints painful swelling of bones, joints or spine $(23.7 \%)(76.3 \%)$;

XI: such as head or neck abnormality swelling on head or neck (4.2\%) (Tsimbiri et al.,2015).
Conclusion: The study concluded that more than one billion United States dollars of pesticides sales was carried out into ten African countries. The review found that there were many health problems encountered by these countries' farmers and the associated factor were lack of attention to safety precautions, poor spraying techniques, carelessness of safekeeping of the chemicals and disposal of empty pesticides containers, consumption of food and beverages while working, lack of personal hygiene, weakness of legislation, and inadequate personnel protective equipment. Many of authors in this review advised that it is essential to rinse the eyes with plenty of clean water if contact occurs by the ocular route and it is crucial to consider the need to decontaminate all the people who work in the emergency system in cases of large contamination. Thus, sufficient knowledge, skill, positive attitude of farmers towards pesticide usage ; the integration of pest management approach, structured legislation and well policy development have significant role to reduce the risk of pesticide within these African countries.

Acknowledgement: I acknowledged all scholars and authors those their papers found on free open access data of engines.

\section{REFERRENCE}

Abang, AF; Kouame C; Abang MM (2006). Vegetable grower's perception of pesticide use practices, cost, and health effects in the tropical region of Cameroon; Adv Crop Sci Tech; 3(3): 174

Abdou, Kh A; Hend, M; Abo El-Atta, K (2018). "Advances in Clinical Toxicology Epidemiology of Pesticides in Developing Countries; 1(1): 1-8

Andert, S; Bürger, J; Stein, S; and Gerowitt, B (2016). The influence of crop sequence on fungicide and herbicide use intensities in North German arable farming,European Journal of Agronomy 77:81-89

Azalekor, WJ; Afun, VK; Osekre, EA; Oyewo, EA (2019). "Health and Environmental Impact of Pesticide Application In-and-Around Cocoa Storage Facilities in Ghana JESPRH; 1: 1-5.

Barchańska, H; Baranowska, I (2009). Procedures for Analysis of Atrazine and Simazine in Environmental Matrices; Vol 200; https://doi.org/10.1007/978-1-4419-0028-9_3

Benaboud JM; Elachouri, J; Oujidi, D; Chafi, A (2014). Pesticides in Oriental Morocco: Knowledge Attitude and Safety; 1: 1-6 
Bhardwaj, SJ (2013). Impact of Pesticides Application in Agricultural Industry: An Indian Scenario." Int. J. Agric. Food Sci. Technol. 4(8): 817-822.

Chikamso, C (2018). Farmers' Perception of the Health Effects of Agrochemicals in Southeast Nigeria; J Health Pollut. 2018 Sep; 8(19): 180901

Clarke, EE; Levy, LS; Spurgeon, A; Calvert, IA (2005). The problems associated with pesticide use by irrigation workers in Ghana," 47(5): 301-308

El-Wakeil N; Shalaby, S; Abdou, G; Salam, A (2013). Pesticide-Residue Relationship and Its Adverse Effects on Occupational Workers," Insectic. Dev. Safer More Eff. Technol; March 2013; DOI: $10.5772 / 54338$

Erhunmwunse, NO; Dirisu, A; Olomukoro, JO (2014). Implications of pesticide usage in Nigeria, Tropical Freshwater Biology, 21 (1):15- 25

Food and Agriculture Organization/FOA/ (2014). Agriculture, Forestry and Other Land Use Emissions by Sources and Removals by Sinks: UN FAO, Rome, Italy; 14(1): 1990-2011.

Food and Agriculture Organization of the United Nations/FOA/ (2018). Encyclopedia of Toxicology: Third Edition, 2018.

Furio, M.; Bernardes, F; Pazin, ML; Pereira, C; Dorta, DJ (2015). Impact of Pesticides on Environmental and Human Health Impact of Pesticides on Environment \& human health," no. August, 2015

Hossain, F; Pray, CE; Lu, YJ; Huang, CF; Hu, R (2004). Genetically modified cotton and farmers' in China," Int J Occup Environ Health; 10:296-303

Hruska, AJ; Corriols, M (2002).The impact of training in integrated pest management among Nicaraguan maize farmers: Increased net returns and reduced health risk," Int. J. Occup. Environ. Health, International journal of occupational and environmental health 8(3):191-200

Imane, B; Mariam, A; Chakib, N; Ahmed, Z; Samir, EJ. ;. Karima, ER (2016). Pesticide Use Pattern among Farmers in a Rural District of Meknes: Morocco," OALib, 03(12): 1-19.

Jean S; Benoit, NM. Edouard, NA; Srivastava, L. P (2018). Pesticide Applications on Some Vegetables Cultivated and Health Implications in Santa, North West-Cameroon; 1: 38-46.
Jepson, PC; Guzy, M; Blaustein, K.; Sow M; Sarr M; Mineau, P; Kegley, S (2014). Measuring pesticide ecological and health risks in West African agriculture to establish an enabling environment for sustainable intensification, Phil. Trans. R. Soc. B 369: 20130491.

Kim, K; Kabir, E; Ara, S (2017). Science of the Total Exposure to pesticides and the associated factors; Sci. Total Environ; 575: 525-535.

Lekei, EE; Ngowi, AV; London, L (2014). Farmers' knowledge, practices and injuries associated with pesticide exposure in rural farming villages in Tanzania," BMC Public Health, 14(1): 1-13

Mabe, FN; Talabi, K; Danso-abbeam, G (2017). Awareness of Health Implications of Agrochemical Use : Effects on Maize Production in Ejura Municipality, Ghana,” 2017: 1-34

Macharia, I; Mithöfer, D; Waibel, H (2009). Potential environmental impacts of pesticides used in the vegetable sub sector in Kenya; 1: 138-151.

Mancini, F; Van Bruggen, JA; Jiggins, CL; Ambatipudi, AC; Murphy, H (2005). Acute Pesticide Poisoning among Cotton Growers," Int. J. Occup. Environ. Health; 3(1): 221-232.

Mengistie, BT.; Mol AP; P. Oosterveer PM (2017). Pesticide use practices among smallholder vegetable farmers in Ethiopian Central Rift Valley," Environ. Dev. Sustain.; 19(1): 301-324.

Michael, J; Madimetja J; Wepener V (2014). "Prioritizing agricultural pesticides used in South Africa based on their mobility and potential human health effects," Environ. Int.62:31-40.

Mulu, K.; Lamoree M; M. Weiss, JM; De Boer, J (2018). Import, disposal, and health impacts of pesticides in the East Africa Rift: A review on management and Policy analysis, J. Crop Prot; 112: 322-331.

Naidoo, S; London L; Burdorf, AR.; Naidoo, N; Kromhout, H (2006). Agricultural Activities, Pesticide Use and Occupational Hazards among Women Working in Farming in Northern KwaZulu-Natal, South Africa; 1: 218-224.

Negatu, B; Kromhout,H ; Mekonnen, Y ; Vermeulen R (2016). A Cross-Sectional Comparative Study on Knowledge Attitude and Practice of Farmers on 
use of Chemical Pesticides in Ethiopia," Ann Occup Hyg; 60(5):551-66.

Ngowi, AVF; Maeda, DN; Partanen, TJ; Sanga, MP; Mbise, G (2002). Health Impact of Exposure to Pesticides in Agriculture in Tanzania. Academic Dissertation; https://trepo.tuni.fi/handle/10024/67224

Ngowi, AV; Mbise, TJ; Ijani, AS; London, L; Organ, C (2007). Ajayi, "Smallholder vegetable farmers in Northern Tanzania: Pesticides use practices, perceptions, cost and health effects," Crop Prot; 26(11): 1617-1624

Nicolopoulou-stamati, P (2016). Chemical Pesticides and Human Health: The Urgent Need for a New Concept in Agriculture," 4(1): 1-8.

Nigatu, AW; Bråtveit, M; Moen, BE (2016). Selfreported acute pesticide intoxications in Ethiopia," BMC Public Health; .1(1): 1-8.

Nkontcheu, K; D. Brice, D (2017). Environmental and Human Health Assessment in Relation to Pesticide Use by Local Farmers; Fako Patricia Asanga Bi Fai," 13(21): 454-473

Ochieng, AA; Dalvie MA; Little, F; Kromhout, H (2013). "Relationship between environmental exposure to pesticides and anthropometric outcomes of boys in the rural Western Cape, South Africa," South African Med. J.; 103(12): 942-947.

Oluwole, O; Cheke, RA (2009). Health and environmental impacts of pesticide use practices: A case study of farmers in Ekiti State, Nigeria," Int. J. Agric. Sustain.; 7(3):153-163

Oluyede, CA; Festus KA (2007). Akinnifesi, 'Farmers' understanding of pesticide safety labels and field spraying practices, "Scientific Research and Essay"; 2 (6):204-210.

Okonya, JS; Kroschel,JK (2015). A Cross-Sectional Study of Pesticide Use and Knowledge of Smallholder Potato Farmers in Uganda, Journal of Biomedicine and Biotechnology; 2015(759049):9.

Quinn, LP; DeVos, BJ; Fernandes-Whaley, CM; Roos; H; Bouwman, H; Kylin, RP; Den Berg J (2011). Pesticide Use in South Africa: Reviewed: March 25th 2011Published: October 21st 2011; DOI: $10.5772 / 16995$
Saidi, I; Mouhouche, F; Abri, H; Hassan, B (2016). Determination of pesticide residues on tomatoes from greenhouses in Boudouaou Algeria," Qual. Assur. Saf. Crop. Foods; 9(2): 207-212.

Scott, DC (2013). World's Biggest Public Companies, retrieved from https://www.forbes.com/sites/

Selim, MI; W. J. Popendorf, WJ (2009). Pesticide Contamination of Surface Water in Egypt and Potential Impact," J. Toxicolo. 4: 1-9.

Soltani, N (2014). Evaluating the effects of pesticides used in East-Algerian orchards on Apis mellifera intermissa: enzymatic activity of acetylcholinesterase. Aca. J. Ento.; 7 (4): 128-133.

Stadlinger, N; Mmochi, AJ; Kumblad, L (2011). Pesticide use among smallholder rice farmers in Tanzania Pesticide use among smallholder rice farmers in Tanzania; J. E. Dev. 13(3):641-656.

Statistics South Africa Annual Report /SSA/ (2003/2004). Pesticide Import https://www.gov.za/documents/st

Tambe, AB; Mbanga, BMR; Nzefa DL; Nama. MG (2019). Pesticide usage and occupational hazards among farmers working in small-scale tomato farms in Cameroon; 1: 0-6.

Tsimbiri, PF; Moturi WN; Sawe, J; Henley, P; Bend, JR (2015). Health Impact of Pesticides on Residents and Horticultural Workers in the Lake Naivasha Region, Kenya," no. April, 2015.

World Health Organization-Food and Agriculture Organization /WHO-FAO/ (2018). Global situation of pesticide management in agriculture and public health: No pages: 73: ISBN: 978-92-4

Yáñez, L; Deogracias, O; Jaqueline, C ; Lilia B ; Leticia, C; Jesús, M; Lourdes M; Edelmira GN; Fernando DB (2002). Overview of Human Health and Chemical Mixtures: Problems Facing Developing Countries; J. Environmental Health Perspectives; 110 (1): 901-909

Zineb, N ; Latifa, A.; Zakaria, A; Maria, W; Abdelmajid, S; Abdelrhani, M; Rachida, SB (2014). "Epidemiology and risk factors of voluntary pesticide poisoning in Morocco (20082014): $1-7$ 